Review

\title{
Let-7 in Cardiovascular Diseases, Heart Development and Cardiovascular Differentiation from Stem Cells
}

\author{
Mei-Hua Bao ${ }^{1,2, \dagger}$, Xing Feng ${ }^{3, \dagger}$, Yi-Wen Zhang ${ }^{1}$, Xiao-Ya Lou ${ }^{1}$, Yu Cheng ${ }^{1}$ and \\ Hong-Hao Zhou ${ }^{1, *}$
}

1 Institute of Clinical Pharmacology, Central South University, Changsha 410078, China;

E-Mails: mhbao78@163.com (M.-H.B.); zjzyw2003@163.com (Y.-W.Z.);

1xy_csu2013@163.com (X.-Y.L.); csuicp@163.com (Y.C.)

2 Department of Pharmacy, Changsha Medical University, Changsha 410219, China

3 College of Medicine, Hunan Normal University, Changsha 410006, China;

E-Mail: fengxing01_2013@163.com

$\dagger$ These authors contributed equally to this work.

* Author to whom correspondence should be addressed; E-Mail: hhzhou@csu.edu.cn;

Tel.: +86-731-8480-5380; Fax: +86-731-8235-4476.

Received: 24 September 2013; in revised form: 30 October 2013 / Accepted: 4 November 2013 / Published: 21 November 2013

\begin{abstract}
The let-7 family is the second microRNA found in C. elegans. Recent researches have found it is highly expressed in the cardiovascular system. Studies have revealed the aberrant expression of let-7 members in cardiovascular diseases, such as heart hypertrophy, cardiac fibrosis, dilated cardiomyopathy (DCM), myocardial infarction (MI), arrhythmia, angiogenesis, atherosclerosis, and hypertension. Let-7 also participates in cardiovascular differentiation of embryonic stem cells. TLR4, LOX-1, Bcl-xl and AGO1 are by now the identified target genes of let-7. The circulating let-7b is suspected to be the biomarker of acute MI and let-7i, the biomarker of DCM. Further studies are necessary for identifying the gene targets and signaling pathways of let-7 in cardiovascular diseases. Let- 7 might be a potential therapeutic target for cardiovascular diseases. This review focuses on the research progresses regarding the roles of let-7 in cardiovascular development and diseases.
\end{abstract}

Keywords: let-7; cardiovascular disease; cardiovascular differentiation; heart development; biomarker 


\section{Introduction}

MicroRNAs (miRNA) are small, endogenous, noncoding RNAs, consisting of 21-25 nucleotides. These small single strand miRNAs target one or more mRNAs, and regulate the expression of the target gene by degradation, translation inhibition, or translational activation of their target mRNA [1,2]. It has been reported that miRNAs may directly regulate roughly one third of the genes in a cell [3].

The first miRNA, lin-4, was discovered in 1993 in C. elegans [4]. Let-7 was the second miRNA found also in $C$. elegans. Both lin-4 and let-7 regulate the development of $C$. elegans [5]. For the time being, more than 2000 miRNAs have been discovered in humans [6].

The human let-7 family contains 13 members located in 9 chromosomes. These members are respectively let-7a-1, let-7a-2, let-7a-3, let-7b, let-7c, let-7d, let-7e, let-7f-1, let-7f-2, let-7g, let-7i mir-98, and mir-202 [7]. Some of them are located in genome as clusters. For example, let-7a-1, let-7d and let-7f-1 form the intergenic cluster mapped to chromosome $9 q 22.32$, whereas let- $7 b$ and let-7a-3 form the intergenic cluster mapped to chromosome 22q13.31.

Many studies have identified let-7 as a tumor suppressor, which is down-regulated or lost in many human cancers. The restoration of let-7 expression may be a useful therapeutic option for cancers $[8,9]$. More recently, the roles of let-7 in cardiovascular biology and disease have received significant attentions (Figure 1). Let-7 have been found to be highly expressed in all major types of cardiovascular cells, including vascular smooth muscle cells (VSMC) [10], endothelial cells (EC) [11], cardiomyocytes [12-14], and coronary arterial smooth muscle cells [15]. Particularly for ECs, different let-7 levels have been observed in different EC types, such as HUVEC, human brain microvascular endothelial cell (HBMVEC), human coronary endothelial cells (HCECs), and human pulmonary artery endothelial cells (HPAECs), suggesting that let-7 contribute to the unique phenotypic diversity of ECs [16].

Figure 1. The timeline of let-7 discovery in cardiovascular diseases.

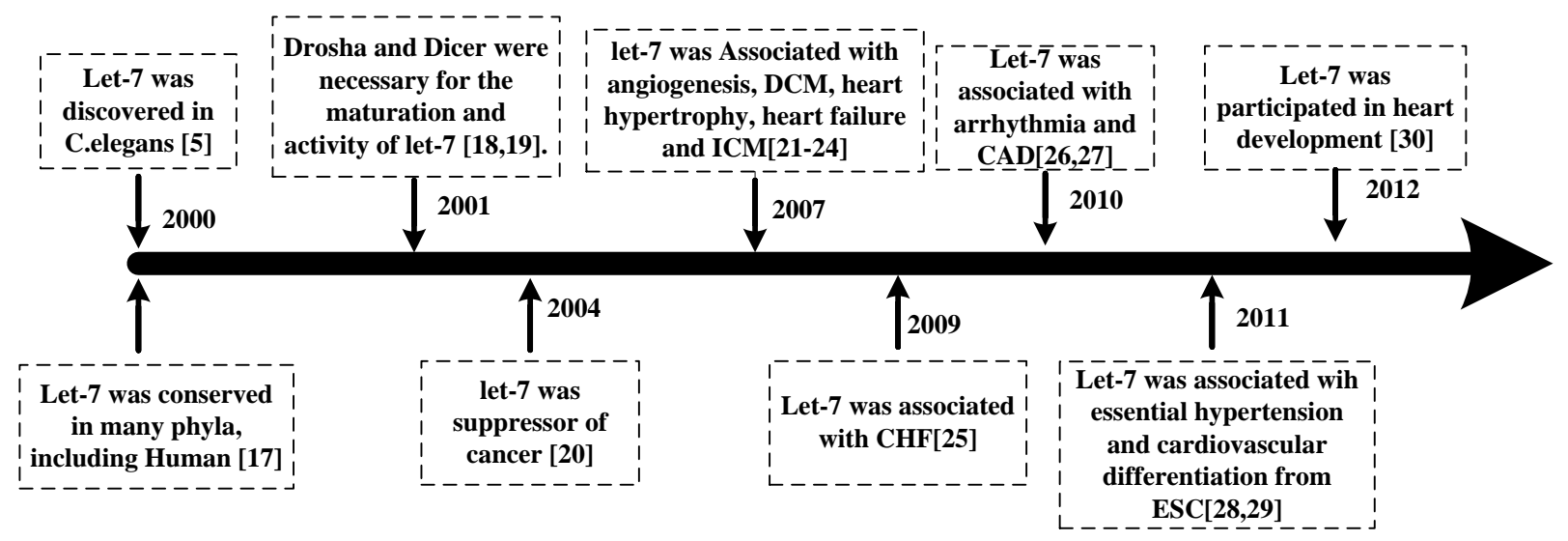

The let-7 family has been discovered to play important roles both in cardiovascular biological procedures and cardiovascular diseases. It acts as a switch and regulator in the development, functions and diseases of cardiovascular system. Although the precise roles of let-7 in these processes are unclear, more and more its potential target genes involved in cardiac signaling and transcription pathways have become apparent during the last years. Here, we review the research progress regarding the roles of let-7 in cardiovascular development and diseases. 


\section{Let-7 in Cardiovascular Diseases}

\subsection{Let-7 in Cardiac Hypertrophy, Heart Development and Cardiac Fibrosis}

Let-7 was first identified as an essential developmental gene in C. elegans, and was demonstrated to be a regulator for stem-cell differentiation in C. elegans, as well as cell proliferation and differentiation in cancer cells. It can thus be reasonable to hypothesize that they may play important roles in cardiac hypertrophy, heart development and heart fibrosis. This hypothesis of let-7 has been clarified by several researches both in vitro and in vivo [31].

Cardiac hypertrophy is a pathological manifestation in chronically stressed hearts and is a significant factor in the pathogenesis of heart failure. In the pathogenesis of hypertrophy, complex signaling networks have been discovered in the latest decades. Recently, the role of miRNAs in cardiogenesis has received great attention. The miR-1, miR-133, miR-126 and miR-143/145 have been confirmed to parcitipate in the cardiac development and hypertrophy [32,33]. A commonly used mouse model of postnatal hypertrophy, transverse aortic constriction (TAC), was adopted by the Sayed D group to investigate miRNAs on postnatal cardiac pathophysiology. They found a complex array of miRNAs is dysregulated, including let-7d been down-regulated and let-7b/c been up-regulated after 14 days of TAC [21]. A very recent study by Yang et al. on pressure-overloaded or angiotensin II treated hearts and isolated cardiomyocytes reported that miR-98 along with other let-7 members were up-regulated [34,35]. Since pressure-overload and angiotensin II are two crucial factors in heart hypertrophy, the results imply that miR-98 and let-7 might play important roles in heart hypertrophy. Although the precise function and signal pathway of let-7 in cardiac hypertrophy is still unclear, the role of a redox- dependent protein, Thioredoxin 1 (Trx1), has been recognized. Trx1 suppresses cardiac hypertrophy by modifying histone deacetylase (HDAC) class II and apoptosis signal-regulating kinase [36,37]. MiR-98 is downstream effector of Trx-1 with potential importance, and cyclin D2 was a functional target of miR-98. Therefore, the Ang II/Trx-1/miR-98/Cyclin $\mathrm{D}_{2}$ signaling pathway form a negative-feedback loop to suppress Ang II induced heart hypertrophy [34,35].

Cardiac fibrosis is a common end-stage pathologic manifestation of several cardiovascular diseases. Fibroblasts are the major sources of extracellular matrix (ECM) during cardic fibrosis. The origin of resident cardiac fibroblasts is thought to be derived from embryonic mesenchymal cells in response to myocardial infarction. Recent studies suggest that adult fibroblast-like cells, originated from endothelial cells by endothelial-to-mesenchymal transition (EndMT), contribute to the pathogenesis of cardic fibrosis $[38,39]$. MiRNA array data reveals that let-7c and let-7g along with other miRNAs are significantly elevated during EndMT [40], indicating that let-7 might take part in EndMT.

\subsection{Let-7 in Myocardial Infarction (MI) and Heart Failure}

MI is a severe disease causing cardiac injuries and even heart failure. To investigate whether let-7 members participate in MI and heart failure, several studies have been undertaken. An in vitro study demonstrated that let-7f was up-regulated in myocardial ischemia [26], and an in vivo study found let-7c was up-regulated in biopsy specimens of 67 patients diagnosed as suffering aortic stenosis, ischemic cardiomyopathy (ICM), or idiopathic cardiomyopathy [22]. A "group analysis" was executed by Shi et al. in 2009 [25]. They found that let-7 members were up-regulated at the significant 
FDR (false discovery rate) of $14 \%$, confirming the relationship between the let-7 family (let-7b/7c/7d/7e/miR-98) and congestive heart failure (CHF) [25]. These findings suggest that let-7 might be an active role in the pathogenesis of $\mathrm{MI}$ and heart failure. However, the effects and mechanisms of let-7 on MI and heart failure are still to be investigated in further studies.

Interestingly, Thum et al. [23] found the let-7c expression alterations were strikingly similar in failing human hearts and fetal hearts (2.2 folds in failing hearts and 2.9 folds in fetal hearts compared with healthy hearts respectively). Moreover, transfection of cardiomyocytes with a set of fetal miRNAs induced cellular hypertrophy as well as changes in gene expressions similar to those in the failing heart. Since chronic heart failure is characterized by reactivation of a fetal gene program, this research demonstrates that miRNAs (including let-7) might be responsible for the gene expression changes in failing heart. Development of drugs and molecules specifically regulating cardiac miRNAs (including let-7) followed by the subsequent normalization of altered target expression may lead to novel treatments for heart failure [23].

\subsection{Let-7 in Dilated Cardiomyopathy (DCM)}

DCM is the most common form of cardiomyopathy associated with heart failure. During the pathogenesis of DCM, toll-like receptors 4 (TLR4) has been found to be an important participator. TLR4 leads to the expression of nuclear factor $\kappa \mathrm{B}$, and is involved in the downstream of key pro-inflammatory cytokines in the myocardium from DCM patients [41]. It has been shown that let-7i target TLR4 at the post-transcription stage and limits the expression of this receptor [24]. In vivo study on DCM patients confirmed the negative relationship of let-7i and TLR4. In the study, the expression between let-7i was down-regulated in DCM patients compared with the control group, and the DCM subgroup with low let-7i levels was associated with poor clinical outcomes [12]. This consequently implies that let-7i might be a novel biomarker for clinical outcomes for patients with DCM (Figure 2). Besides DCM, hints also exist that let-7 participate in the cardiomyopathy caused by some drugs. Fu et al. found that let-7g was suppressed significantly in the doxorubicin-induced cardiomyopathy [42].

Figure 2. Targets of let-7 in dilated cardiomyopathy (DCM), arrhythmia and heart development. The solid arrow indicates the confirmed targets and the dotted arrow indicates the predicted targets of let-7.

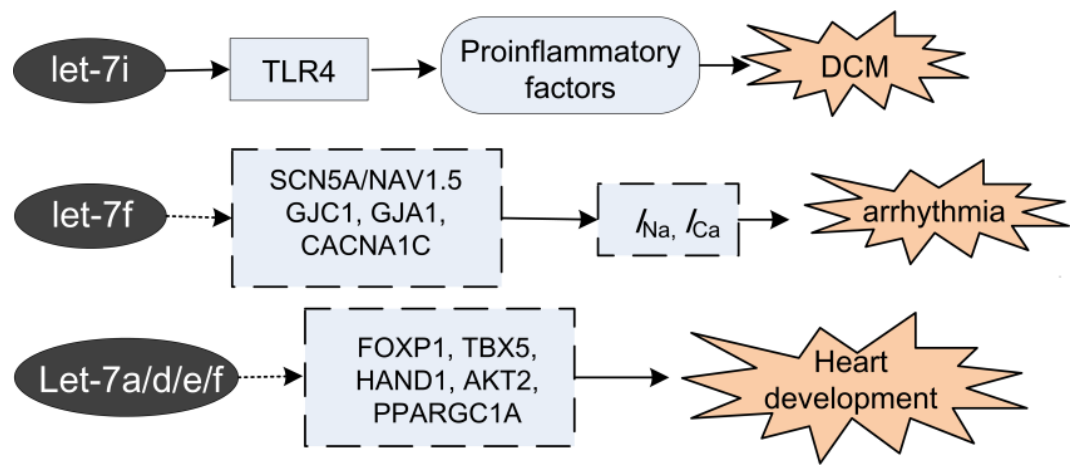




\subsection{Let-7 in Arrhythmia}

Excitability is a fundamental feature of cardiac cells. Cardiac excitability is conferred by heart electrical activities orchestrating by a matrix of ion channels and transporters, the trans-membrane proteins that control the movement of ions across the cytoplasmic membrane of cardiomyocytes. The interplay of ion channels maintain the normal heart rhythm. Channelopathies, disease caused by dysfunction of the ion channels, can render electrical disturbances predisposing to cardiac arrhythmias [43]. The involvement of miRNAs in arrhythmia has been recognized recently [26,44-46]. Let-7 is the fifth most abundant miRNA in myocardium, and is predicted to regulate main cardiac conduction by targeting SCN5A (Nav1.5 for intracellular conduction), GJC1 (Cx45 for intercellular conduction), GJA1 (Cx43 for intercellular conduction) and CACNA1C (Cav1.2 for the characteristic long plateau of the cardiac action potential and excitation-contraction coupling), resulting in the $I_{\mathrm{Na}}, I_{\mathrm{Ca}}$ reduction and eventually account partly for the conduction damage and arrhythmias (Figure 2) [26]. Furthermore, it has been shown that by affecting $\mathrm{Na}^{+}$and $\mathrm{Ca}^{2+}$ channels, let-7f participate in arrhythmias caused by MI [26].

\subsection{Let-7 in Angiogenesis}

In vascular development and homeostasis, the formation of new blood vessel through the process of angiogenesis is critical. Endothelial cells are key regulators of different aspects of vascular biology, including the formation of new blood vessels (angiogenesis). Aberrant angiogenesis leads to numerous disorders, such as cancer and ischemia. Several studies have reported the important roles of miRNAs in regulating ECs in angiogenesis, e.g., miR-126, miR-17 92 cluster, miR-378 and miR-296 [47-51]. Let-7 has been found highly expressed in HUVECs [52], and exhibited to play critical roles in angiogenesis. The effects of let-7 on angiogenesis were first identified by Dicer and Drosha knockdown method. After Drosha and Dicer knockdown, let-7a, let-7b, let-7c, let-7f and let-7g were reduced by more than $30 \%$. The reduction of let- $7 \mathrm{f}$ has been verified to significantly impair the sprout formation [52]. Similar effects were found for let-7a [53] and let-7b [54]. Although the detailed signal network is yet not determined, many angiogenesis-related factors have been shown to participate in let-7 regulated angiogenesis, such as thrombospondin-1 [53,54], thrombospondin-2 [55], TIMP-1 [54], Nrp-2 and c-Met [56], TEK/Tie-2, KDR/VEGFR2 and Tie-1 [53]. A very recent study found the hypoxia-inducible factor $1 \alpha$ (HIF1 $\alpha$ )/let-7/argonaute 1(AGO1)/VEGF signal pathway in hypoxia-induced angiogenesis. HIF $1 \alpha$ is a key transcription factor, which up-regulates the expressions of let-7, and let-7 targeted AGO1, resulting in the translational desuppression of VEGF mRNA as well as angiogenesis [11] (Figure 3). These findings provide evidence for an angiogenic pathway involving let-7 that targets $A G O 1$ and suggests that this pathway may be a suitable target for anti- or pro-angiogenesis strategies. Interestingly, compared with other studies [53,54], an inverse regulative direction of let-7's was found in this research. This conflict might indicate a complex mechanism of let-7 on angiogenesis, which still need further studies.

Other interesting findings about let-7 suggest that it might participate in cell to cell actions in angiogenesis. For instance, in glioma cells co-incubated human brain microvascular endothelial cells, and in neural stem/progenitor cells (NSPC) co-incubated ECs also, let-7 members display decreased 
levels [49,57]. Glioma cells and NSPC are considered to promote tumor or brain angiogenesis [58]. Although the contribution of let-7 on glioma cell-induced tumor angiogenesis is still to be clarified, the effects of let-7i on NSPC-induced brain angiogenesis may partly be obtained through the SMAD2/SMAD3 and p53/IGF-1R/p-mTOR signaling pathways [57] (Figure 3).

Figure 3. Roles and signaling pathways of let-7 in hypoxia- and neural stem/progenitor cells (NSPCs)-induced angiogenesis. Hypoxia treatment on endothelial cells (ECs) induced angiogenesis through hypoxia-inducible factor $1 \alpha$ (HIF1 $\alpha$ )/let-7s/(AGO1)/VEGF signaling pathway. In ECs co-incubated with NSPCs, pro-angiogenic factors released by the NSPCs induced angiogenesis through SMAD2 (SMAD3), and p53/IGF-1R/p-mTOR signaling pathways.

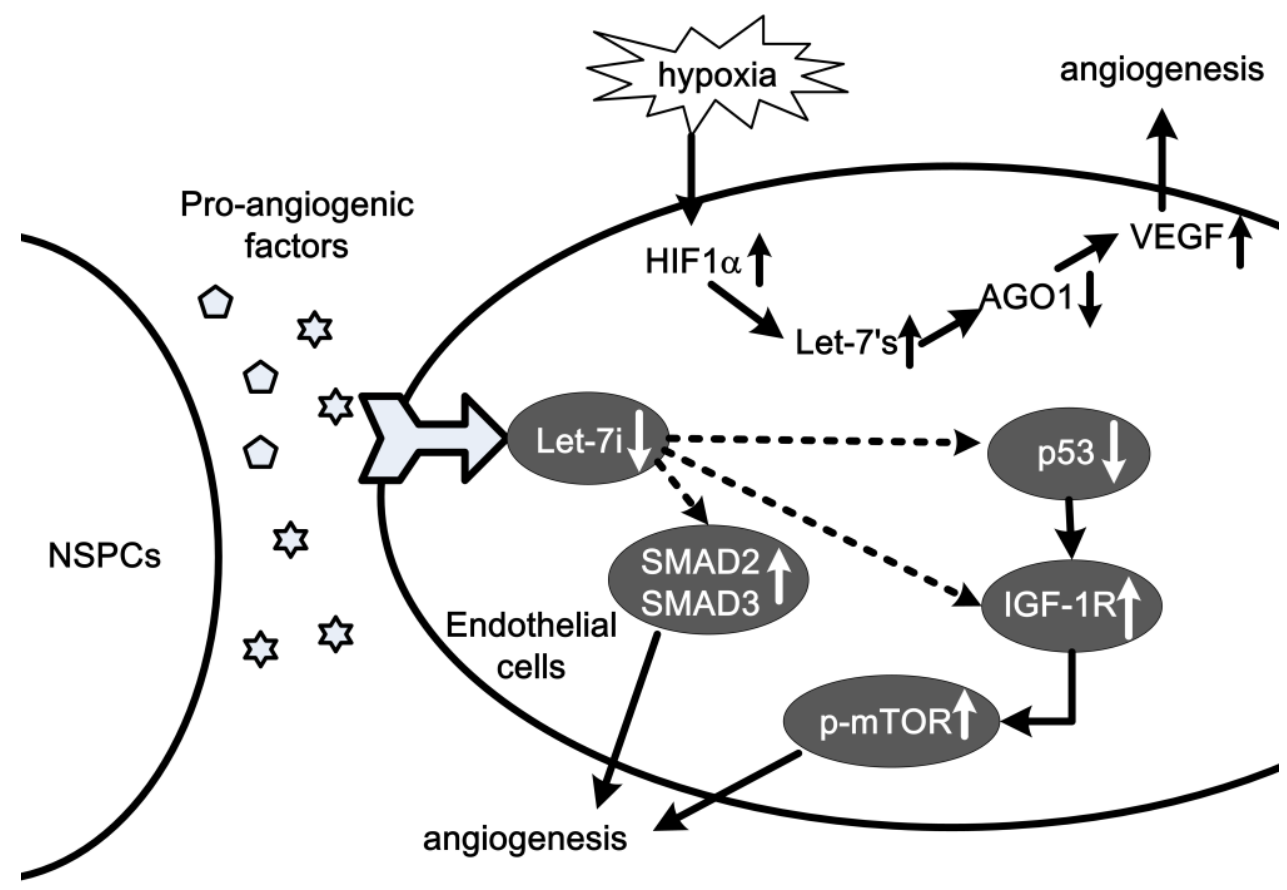

\subsection{Let-7 in Atherogenesis and Coronary Artery Disease}

Atherosclerosis (AS) is a chronic multifactorial inflammatory disease with a high prevalence and has become the major cause of death worldwide. The principal clinical manifestations of atherosclerosis are represented by coronary artery disease (CAD), acute myocardial infarction (AMI), cerebral stroke and peripheral vascular disease. The vascular EC injuries are considered to be the initial step of AS, and subsequent leukocytes invasion, vascular smooth muscle cell proliferation and foam cell formation all contribute to the atherogenesis [59-61]. Let-7s are abundantly expressed miRNAs in both ECs and VSMCs. Their roles on AS and CAD have also been demonstrated recently by several studies in vivo and in vitro $[10,62,63]$. Let-7g has shown to be reduced in oxLDL treated VSMCs, and this reduction may partially be responsible to the oxLDL-induced cell proliferation and migration [63], autophagy and apoptosis [10]. Lectin-like oxidized LDL receptor-1 (LOX-1), a surface scavenger receptor for oxLDL, has been identified to be the target of Let-7g. The downstreams of LOX-1, such as $\mathrm{Ca}^{2+}$, PKC and OCT-1, are subsequently impacted by let-7g. On the other hand, the transcription factor, OCT-1, also modulates the transcription of let- $7 \mathrm{~g}$ gene. Thus, a negative feedback loop exists between LOX-1 and 
let-7g [63]. Other factors related to VSMCs functions, such as ROS, autophagy-related proteins (expression of beclin-1, LC3-II/LC3-I ratio and Atg5) and apoptosis-related proteins (expression of caspase-3, Bax, Bcl-2 and Bcl-xL), are involved in the effects of let-7g [10]. Nonetheless, in oxLDL-induced EC apoptosis, let-7c seems to be up-regulated, and this up-regulation promotes EC apoptosis by targeting anti-apoptotic protein Bcl-xl [62]. Thus, let-7g might be an anti-atherogenesis factor and let-7c be a pro-atherosclerosis factor (Figure 4).

Figure 4. Roles of let-7 in oxLDL induced VSMCs and ECs apoptosis, proliferation, migration and autophagy. OxLDL induces EC apoptosis via let-7c and subsequent Bcl-xl and Caspase-3. In oxLDL treated VSMCs, oxLDL suppresses let-7g expression via LOX-1/Ca ${ }^{2+} / \mathrm{PKC} / \mathrm{OTC}-1$ signaling pathway, the let-7g then targets on Beclin-1, LC3-II (LC3-I), Atg5, Caspase-3, Bax, Bcl-2, and Bcl-xl, and regulates the proliferation, migration, autophagy and apoptosis of VSMC.

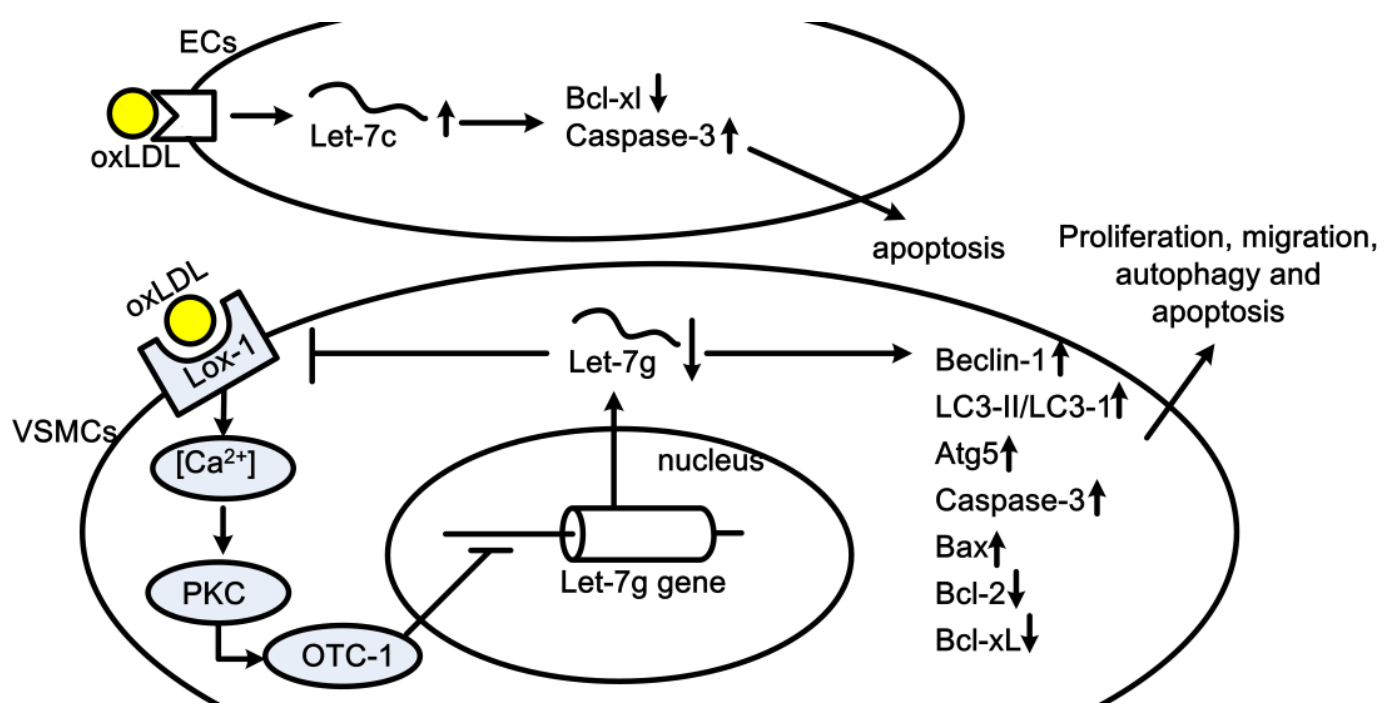

In in vivo studies, let-7g levels were found reduced both in high-fat diet mice and hypercholesterolemia humans, in accordance with in vitro results [60]. Let-7d and let-7i levels are down-regulated in CAD patients [27,64], and let-7s are up-regulated in patients suffering atherosclerotic abdominal aortic aneurysm (AAA) [65]. Intriguingly, there is a negative correlation between let-7i and TLR4 levels in CAD patients, similar to results from in vitro reports [24]. Because TLR4 signal is involved in pro-inflammatory cytokines release and contribute to CAD and heart failure [66], let-7i may be a participator in CAD via TLR4. Via influencing the let-7i expressions, atorvastatin treatment markedly down-regulates TLR4 signal in CAD patients, possibly contributing to the beneficial effects of atorvastatin on these patients [27].

Neointimal formation is a common pathological lesion in various cardiovascular diseases, such as atherosclerosis, coronary heart diseases and transplantation arteriopathy. In the angioplasty neointimal, let-7s are down-regulated dramatically [15]. Though the details of let-7's effects on angioplasty are still unclear, miRNAs may be new therapeutic target for proliferative vascular diseases such as atherosclerosis, postangioplasty restenosis, transplantation arteriopathy, and stroke. 


\subsection{Let-7 in Hypertension}

Essential hypertension is a cause for many diseases, such as stroke, MI, and CHF. Several studies have shown the relationship between miRNAs and hypertension [67-69]. However, the relationship between let-7 and hypertenstion had bot been reported until very recently. Li et al. [70] compared the miRNA expressions in the plasma samples from hypertensive patients and healthy control subjects. The expressions of 27 miRNAs were found changed, among with 9 miRNAs were up-regulated, and 18, down-regulated. Particularly, let-7e was found to be regulated up to 1.7 folds of control $(p<0.0001)$. Interestingly, the cellular origin of plasma let-7e seems to be partially from endothelial cells rather than endothelial progenitor cells (EPCs). It was found that let-7e levels in ECs from hypertensive patients were higher than those from control subjects, and in patient plasma samples, this similar expression trend was also observed. On the other hand, the changes in let-7e levels in EPCs were opposite to those in plasma. No differences in let-7e levels in peripheral blood mononuclear cells were observed between the hypertensive patients and control subjects. The targets and the role of let-7e in hypertension are still open for further exploration.

\section{Let-7 in Heart Development}

The roles of let-7 on heart development were evaluated by fetal mouse heart, namely, at 4 key time-points [embryonic (E) day E12.5, E14.5, E16.5 and E18.5] during its development. In the longer development group, several members of the let-7 (let-7a/7d/7e/7f) were up-regulated. Bioinformatic analysis predicts five cardiac development related genes (FOXP1, TBX5, HAND1, AKT2 and $P P A R G C 1 A$ ) to be the targets of let- $7 \mathrm{a} / 7 \mathrm{~d} / 7 \mathrm{e} / 7 \mathrm{f}$ (Figure 2). These findings indicate that let-7 might participate in normal heart development, and the aberrant expression of let-7 might result in congenital heart disease [30].

\section{Let-7 in Cardiovascular Differentiation of Embryonic Stem Cells}

It is well known that postnatal hearts are unable to repair following injuries. With more and more people becoming victims of heart failure worldwide, the embryonic stem cells (ESCs) differentiated cardiovascular has gained great attentions recently. During the process of human ESC differentiation into myocardial precursors and cardiomyocytes (CMs), several miRNAs are specifically regulated, and may play important role in supporting the differentiation or provide biomarkers for the stem cell-derived cardiomyocytes. Wong et al. [71] examined $>900$ miRNAs from human ESC to myocardial precursors on day 8 and 14 of the differentiation, and identified 95 miRNAs on day 8 and 67 miRNAs on day 14 . The results exhibit changes in expressions whose magnitudes are more than two folds, and miR-1, miR-133, let-7 as well as miR-125b are among these miRNAs.

Interestingly, in ESCs at different stages of differentiation ESCs, such as undifferentiated hESC, hESC-derived (hE-), fetal (hF-) and adult (hA-) ventricular (V) CMs, let-7s are differently expressed. They are expressed higher in hE-, hA-, and hF-VCMs than in undifferentiated ESCs [28]. Introduction of let-7s can suppress self-renewal in $\operatorname{Dgcr}^{-/-}$ESCs and induce differentiation [29]. These results indicate that let-7 might make important contribution in cardiavascular-oriented ESCs differentiation processes. 
In the cardiovascular differentiation of ESCs, a complex network exists among various miRNAs. For example, miR-125b has been shown to regulate let-7 expression via targeting lin-28, an inhibitor of let-7 [71].

Induced pluripotent stem (iPS) cells are considered to be similar to ESCs [72]. Compared to those in iPS, let-7s are abrogated in iPS-derived cardiomyocytes, and iPS is demonstrated to be effective to cure acute myocardial infarction (AMI) in mice [73].

\section{Circulating Let-7 as a Mediator of Intercellular Communication and as a Biomarker of Cardiovascular Disease}

MiRNAs has been recently revealed to be secreted by donor cells and can influence the gene expressions of recipient cells. Although the secretory mechanisms and its impacts are yet to be explored, the secreted miRNAs have recently been considered as an emerging form of intrercellular communication. Since both actively secreted miRNAs and passively leaked miRNAs can be released in a stable, cell-free form to circulation, they are also called circulating miRNAs [74]. miRNAs can enter the circulation through three pathways: (i) passive leakage from broken cells; (ii) active secretion via microvesicles, including exosomes and shedding vesicles; and (iii) active secretion in conjunction with the RNA-binding protein high-density lipoprotein (HDL) [73]. The circulating let-7b has been reported to be secreted by mouse preadipocyte cell line (3T3-L1) in the form of microvesicles, and might be transferred into macrophages. However, the biological functions of intercellular transfer of miRNAs from donor cells to recipient cells remain unknown [75,76].

Recently, the circulating miRNAs have been reported as potential biomarkers for various pathologic conditions [77-79]. In AMI patients, the authors found let-7b being dramatically inhibited in 4 to $12 \mathrm{~h}$ of the onset of AMI, and reached its expression peak at $8 \mathrm{~h}$, which was similar to the peak time of cardiac troponin I (cTnI), a maker with high specificity for cardiac injury. Results of the receiver operating characteristic (ROC) curve analyses suggest let-7b be of significant diagnostic value for AMI [80]. Thus, in addition to cTnI, let-7b might be a potential combined diagnosis marker to further confirmation of the AMI, since the down-regulation of let-7b is consistent with the up-regulation of cTnI, and the change of let- $7 \mathrm{~b}$ can be detected in a relative short time after onset of AMI. However, further studies are necessary to determine whether or not let-7b can be used as a prognostic indicator. In DCM patients, the expression of let-7i is significantly down-regulated compared with the healthy control group. Further studies discovered that the DCM subgroup with low let-7i levels yielded poor clinical outcomes [12]. This may imply that let-7i be a novel biomarker for clinical outcomes in DCM patients. However, in atherosclerosis patients, let-7f is observed significantly increased in tissue samples, but not in blood samples. Because of the difficulty to obtain tissue samples, let-7f shows little value as a biomarker. However, it may be used as a therapeutic target [81].

\section{Conclusion and Perspective}

Both in vivo and in vitro studies have revealed the aberrant expression of let-7 in diverse cardiovascular diseases, heart development and cardiovascular differentiation, implying they may play important roles in these processes. It should be noted that the expression trends of specific let-7 members are disease- and organ-specific. For example, in most heart diseases (heart hypertrophy, 
ICM, CHF, MI, arrhythmia) and in heart development, let-7s are up-regulated, while in most vascular diseases (angiogenesis, CAD) they are down-regulated. For the expression of a particular group of let-7s, there is a particular pathological process associated. For example, in heart hypertrophy, let-7b/7c/miR-98 are up-regulated and let-7d is down-regulated. These signature patterns can provide aids in the diagnosis and prognosis of human diseases, as evidenced by recent studies on cardiovascular diseases (Figure 5, Table 1) [11,80]. However, better understandings on the functions of let-7s are needed to determine whether let-7s can be potential therapeutic targets or not. Only a handful of targets for let-7s have by now been discovered, such as TLR4, lox-1, Bcl-xl and AGO1. It is critical to identify their gene targets and signaling pathways responsible for their cardiovascular effects in future studies. Moreover, how the expressions of let-7s are regulated in cardiovascular diseases is currently unclear. Studies on the regulation of these aberrantly expressed let-7s are necessary and promising.

Figure 5. Modulation of let-7 in different cardiovascular diseases. Red color indicates let-7s that are significantly up-regulated, green color indicates let-7s that are significantly down-regulated. ICM: ischemic cardomyopathy; CHF: congestive heart failure; MI: myocardial infarction; DCM: dilated cardiomyopathy; CAD: coronary artery disease; AS: atherosclerosis; a: tissue samples; b: circulation (plasma) levels; c: cells levels, d: bioinformatics studies.

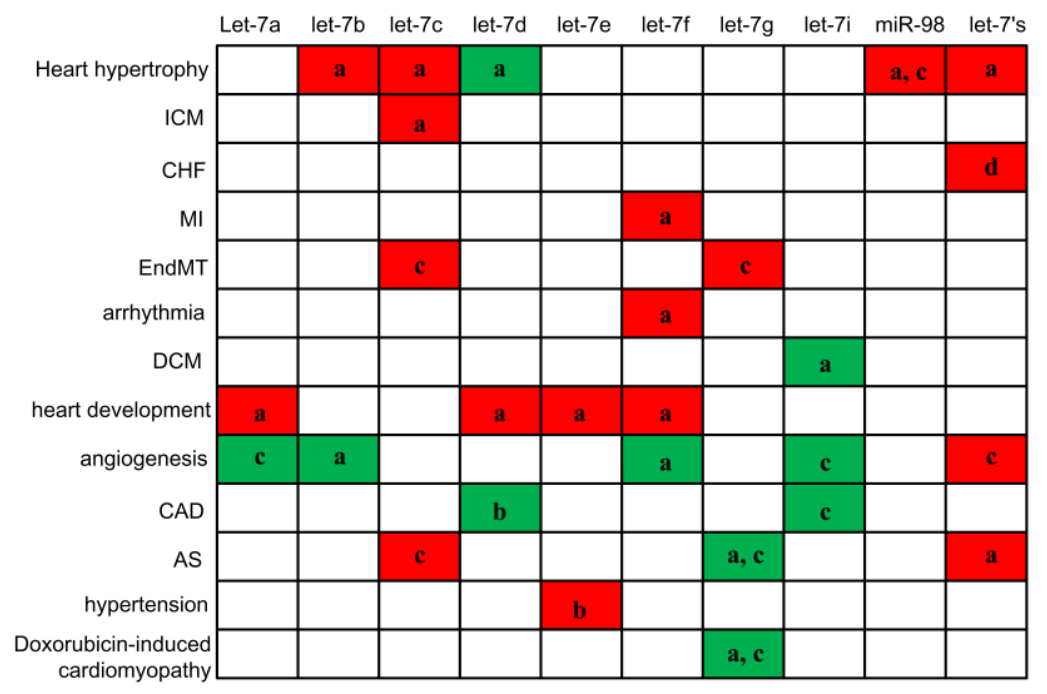

Table 1. Synopsis of let-7 in cardiacvascular diseases, heart development and cardiavascular differentiation from stem cells.

\begin{tabular}{lllll}
\hline $\begin{array}{l}\text { Let-7 } \\
\text { member }\end{array}$ & $\begin{array}{l}\text { Up-/downregulation } \\
\text { during cardiovascular } \\
\text { diseases }\end{array}$ & Tissue or cell samples used & $\begin{array}{l}\text { Predicted (in italic) or } \\
\text { confirmed targeted genes }\end{array}$ & References \\
\hline \multirow{2}{*}{ Let-7a } & Heart development $\uparrow$ & Mouse fetal hearts & $\begin{array}{l}(\text { FOXP1, TBX5, HAND1, } \\
\text { AKT2, PPARGC1A) }\end{array}$ & {$[30]$} \\
\cline { 2 - 5 } & Angiogenesis $\downarrow$ & Human endothelial cells & Nrp-2 & {$[53]$} \\
\hline \multirow{2}{*}{ Let-7b } & Heart hypertrophy $\uparrow$ & Mouse heart & Undetected & {$[21]$} \\
\cline { 2 - 5 } & Angiogenesis $\downarrow$ & Mouse ovary vessel & TIMP-1 c-Met & {$[54]$} \\
\hline
\end{tabular}


Table 1. Cont.

\begin{tabular}{|c|c|c|c|c|}
\hline $\begin{array}{l}\text { Let-7 } \\
\text { member }\end{array}$ & $\begin{array}{l}\text { Up-/downregulation } \\
\text { during cardiovascular } \\
\text { diseases }\end{array}$ & Tissue or cell samples used & $\begin{array}{l}\text { Predicted (in italic) or } \\
\text { confirmed targeted genes }\end{array}$ & References \\
\hline \multirow{4}{*}{ Let-7c } & Heart hypertrophy $\uparrow$ & Mouse heart & Undetected & [21] \\
\hline & $\mathrm{ICM} \uparrow$ & Human left ventricular & Undetected & [22] \\
\hline & EndMT $\uparrow$ & $\begin{array}{l}\text { Mouse cardiac } \\
\text { endothelial cells }\end{array}$ & Undetected & {$[40]$} \\
\hline & $\mathrm{AS} \uparrow$ & human endothelial cells & Bcl-xl & {$[62]$} \\
\hline \multirow{2}{*}{ Let-7e } & Heart development $\uparrow$ & Mouse fetal hearts & $\begin{array}{l}\text { (FOXP1, TBX5, HAND1, } \\
\text { AKT2, PPARGC1A) }\end{array}$ & {$[30]$} \\
\hline & Hypertension $\uparrow$ & $\begin{array}{l}\text { Human plasma samples (the } \\
\text { origin is endothelial cells) }\end{array}$ & Undetected & {$[70]$} \\
\hline \multirow{4}{*}{ Let-7f } & Arrhythmia $\uparrow$ & Rat hearts & Undetected & [26] \\
\hline & $\mathrm{MI} \uparrow$ & Rat hearts & Undetected & {$[26]$} \\
\hline & Heart development $\uparrow$ & Mouse fetal hearts & $\begin{array}{l}\text { (FOXP1, TBX5, HAND1, } \\
\text { AKT2, PPARGC1A) }\end{array}$ & {$[30]$} \\
\hline & Angiogenesis $\downarrow$ & Human endothelial cells & thrombospondin-1, TSP-2 & {$[52]$} \\
\hline \multirow{3}{*}{ Let-7g } & EndMT $\uparrow$ & $\begin{array}{l}\text { Mouse cardiac } \\
\text { endothelial cells }\end{array}$ & Undetected & {$[40]$} \\
\hline & AS $\downarrow$ & VSMCs, and mice aorta & Lectin-like LDL receptor1 & [63] \\
\hline & $\begin{array}{l}\text { Doxorubicin-induced } \\
\text { cardiomyopathy } \downarrow\end{array}$ & $\begin{array}{l}\text { Rat hearts and } \\
\text { cardiac myocytes }\end{array}$ & Undetected & {$[42]$} \\
\hline \multirow{3}{*}{ Let-7i } & $\mathrm{DCM} \downarrow$ & $\begin{array}{l}\text { Endomyocardial } \\
\text { biopsy tissues }\end{array}$ & Toll like receptor 4 & {$[24]$} \\
\hline & Angiogenesis $\downarrow$ & Human endothelial cells & $I G F-I R$ & {$[57]$} \\
\hline & $\mathrm{CAD} \downarrow$ & $\begin{array}{l}\text { THP- } 1 \text { cells and patient blood } \\
\text { monocytes }\end{array}$ & Toll like receptor 4 & {$[64]$} \\
\hline MiR-98 & Heart hypertrophy $\uparrow$ & $\begin{array}{l}\text { Mouse heart, and cardiac } \\
\text { myocyte }\end{array}$ & Thioredoxin 1 & {$[34,35]$} \\
\hline \multirow{6}{*}{ Let-7's } & Heart hypertrophy $\uparrow$ & Mouse heart & Undetected & {$[34]$} \\
\hline & $\mathrm{CHF} \uparrow$ & Bioinformatics studies & Undetected & [25] \\
\hline & Atherosclerotic AAA $\uparrow$ & Human aortic aneurysm & Undetected & {$[65]$} \\
\hline & Angiogenesis $\uparrow$ & Human endothelial cells & Argonaute 1 & {$[11]$} \\
\hline & $\begin{array}{l}\text { ESC differentiation to } \\
\text { myocardiac cells } \uparrow\end{array}$ & $\begin{array}{l}\text { ESCs and ESC-derived } \\
\text { cardiomyocytes }\end{array}$ & Undetected & {$[28,29,71]$} \\
\hline & $\begin{array}{l}\text { iPS differentiation to } \\
\text { cardiomyocytes } \downarrow\end{array}$ & $\begin{array}{l}\text { iPS cells and iPS-derived } \\
\text { cardiomyocytes }\end{array}$ & Undetected & [73] \\
\hline
\end{tabular}

Cardiovascular diseases are the consequences of combined action of many tissue and cells including cardiomyocytes, endothelial cells, white blood cells, and smooth muscle cells. Since the secreted miRNAs have been revealed to play important roles in intra- and inter-cellular communications and multiple pathological processes [70], the identification of the biological roles of circulating let-7s should be done. In summary, the ultimate goal of the research orientation is to obtain let-7s based therapeutic and diagnostic strategies for cardiovascular diseases, to realize roles of let-7s in cardiovascular development, functions, and dysfunctions and to provide new insights into these disorders.

\section{Acknowledgments}

This work was supported by the National Natural Sciences Foundation of China (No. 81300231), Hunan Provincial Natural Sciences Foundation of China (No. 13JJ4112), Hunan Provincial Innovation 
Foundation for Postgraduate (No. CX2013B101) and Hunan Provincial Department of Education Program (No. 11Co152).

\section{Conflicts of Interest}

The authors declare no conflict of interest.

\section{References}

1. Bartel, D.P. MicroRNAs: Genomics, biogenesis, mechanism, and function. Cell 2004, 116, 281-297.

2. Pushparaj, P.N.; Aarthi, J.J.; Kumar, S.D.; Manikandan, J. RNAi and RNAa-The yin and yang of RNAome. Bioinformatics 2008, 2, 235-237.

3. Lewis, B.P.; Burge, C.B.; Bartel, D.P. Conserved seed pairing, often flanked by adenosines, indicates that thousands of human genes are microRNA targets. Cell 2005, 120, 15-20.

4. Lee, R.C.; Feinbaum, R.L.; Ambros, V. The C. elegans heterochronic gene lin-4 encodes small RNAs with antisense complementarity to lin-14. Cell 1993, 75, 843-854.

5. Reinhart, B.J.; Slack, F.J.; Basson, M.; Pasquinelli, A.E.; Bettinger, J.C.; Rougvie, A.E. Horvitz, H.R.; Ruvkun, G. The 21-nucleotide let-7 RNA regulates developmental timing in Caenorhabditis elegans. Nature 2000, 403, 901-906.

6. MiRBase. Available online: http://www.mirbase.org/cgi-bin/browse.pl?org=hsa8 (accessed on 14 September 2013).

7. Roush, S.; Slack, F.J. The let-7 family of microRNAs. Trends Cell Biol. 2008, 18, 505-516.

8. Boyerinas, B.; Park, S.M.; Hau, A.; Murmann, A.E.; Peter, M.E. The role of let-7 in cell differentiation and cancer. Endocr. Relat. Cancer 2010, 17, F19-F36.

9. Charles, D.J.; Aurora, E.K.; Giovanni, S. The let-7 microRNA represses cell proliferation pathways in human cells. Cancer Res. 2007, 67, 7713-7722.

10. Ding, Z.; Wang, X.; Schnackenberg, L.; Khaidakov, M.; Liu, S.; Singla, S.; Dai, Y.; Mehta, J.L. Regulation of autophagy and apoptosis in response to ox-LDL in vascular smooth muscle cells, and the modulatory effects of the microRNA hsa-let-7g. Int. J. Cardiol. 2013, doi:10.1016/j.ijcard.2012.12.045.

11. Chen, Z.; Lai, T.C.; Jan, Y.H.; Lin, F.M.; Wang, W.C.; Xiao, H.; Wang, Y.T.; Sun, W.; Cui, X.; Li, Y.S.; et al. Hypoxia-responsive miRNAs target argonaute 1 to promote angiogenesis. J. Clin. Investig. 2013, 123, 1057-1067.

12. Mamoru, S.; Yoshitaka, M.; Yuji, T.; Tsuyoshi, T.; Motoyuki, N. A cellular microRNA, let-7i, is a novel biomarker for clinical outcome in patients with dilated cardiomyopathy. J. Card. Fail. 2011, 17, 923-929.

13. Lagos-Quintana, M.; Rauhut, R.; Yalcin, A.; Meyer, J.; Lendeckel, W.; Tuschl, T. Identification of tissue-specific miRNAs from mouse. Curr. Biol. 2002, 12, 735-739.

14. Rao, P.K.; Toyama, T.; Chiang, H.R.; Gupta, S.; Bauer, M.; Medvid, R.; Reinhardt, F.; Liao, R.; Krieger, M.; Jaenisch, R.; et al. Loss of cardiac microRNA-mediated regulation leads to dilated cardiomyopathy and heart failure. Circ. Res. 2009, 105, 585-594. 
15. Ji, R.; Cheng, Y.; Yue, J.; Yang, J.; Liu, X.; Chen, H.; Dean, D.B.; Zhang, C. MicroRNA expression signature and antisense-mediated depletion reveal an essential role of microRNA in vascular neointimal lesion formation. Circ. Res. 2007, 100, 1579-1588.

16. McCall, M.N.; Kent, O.A.; Yu, J.; Fox-Talbot, K.; Zaiman, A.L.; Halushka, M.K. MicroRNA profiling of diverse endothelial cell types. BMC Med. Genomics 2011, 4, 78-91.

17. Pasquinelli, A.E.; Reinhart, B.J.; Slack, F.; Martindale, M.Q.; Kuroda, M.I.; Maller, B.; Hayward, D.C.; Ball, E.E.; Degnan, B.; Muller, P.; et al. Conservation of the sequence and temporal expression of let-7 heterochronic regulatory RNA. Nature 2000, 408, 86-89.

18. Hutvagner, G.; Mclachlan, J.; Pasquenelli, A.E.; Balint, E.; Tuschl, T.; Zamore, P.D. A cellular function for the RNA-interference enzyme Dicer in the maturation of the let-7 small temporal RNA. Science 2001, 293, 834-838.

19. Grishok, A.; Pasquinelli, A.E.; Conte, D.; Li, N.; Parrish, S.; Ha, I.; Baillie, D.L.; Fire, A.; Ruvkun, G.; Mello, C.C. Genes and mechanisms related to RNA interference regulate expression of the small temporal RNAs that control C. elegans developmental timing. Cell 2001, 106, 23-34.

20. Takamizawa, J.; Konish, H.; Yanagisawa, K.; Tomida, S.; Osada, H.; Endoh, H.; Harano, T.; Yatabe, Y.; Nagino, M.; Nimura, Y.; et al. Reduced expression of the let-7 microRNAs in human lung cancers in association with shortened postoperative survival. Cancer Res. 2004, 64, 3752-3756.

21. Sayed, D.; Hong, C.; Chen, I.Y.; Lypowy, J.; Abdellatif, M. MicroRNAs play an essential role in the development of cardiac hypertrophy. Circ. Res. 2007, 100, 416-424.

22. Ikeda, S.; Kong, S.W.; Lu, J.; Bisping, E.; Zhang, H.; Allen, P.D.; Golub, T.R.; Pieske, B.; $\mathrm{Pu}$, W.T. Altered microRNA expression in human heart disease. Physiol. Genomics 2007, 31, 367-373.

23. Thum, T.; Galuppo, P.; Wolf, C.; Fiedler, J.; Kneitz, S.; van Laake, L.W.; Doevendans, P.A.; Mummery, C.L.; Borlak, J.; Haverich, A.; et al. MicroRNAs in the human heart: A clue to fetal gene reprogramming in heart failure. Circulation 2007, 116, 258-267.

24. Chen, X.M.; Splinter, P.L.; O’Hara, S.P.; LaRusso, N.F. A cellular micro-RNA, let-7i, regulates Toll-like receptor 4 expression and contributes to cholangiocyte immune responses against Cryptosporidium parvum infection. J. Biol. Chem. 2007, 282, 28929-28938.

25. Shi, G.; Cui, Q.; Zhang, Y. MicroRNA set: A novel way to uncover the potential black box of chronic heart failure in microrna microarray analysis. J. Comput. Sci. Syst. Biol. 2009, 2, 240-246.

26. Luo, X.; Zhang, H.; Xiao J.; Wang, Z. Regulation of human cardiac ion channel genes by microRNAs: Theoretical perspective and pathophysiological implications. Cell Physiol. Biochem. 2010, 25, 571-586.

27. Fichtlscherer, S.; Rosa, S.D.; Fox, H.; Schwietz, T.; Fischer, A.; Liebetrau, C.; Weber, M.; Hamm, C.W.; Roxe, T.; Muller-Ardogan, M.; et al. Circulating microRNAs in patients with coronary artery disease. Circ. Res. 2010, 107, 677-684.

28. Fu, J.D.; Rushing, S.N.; Lieu, D.K.; Chan, C.W.; Kong, C.W.; Geng, L.; Wilson, K.D.; Chiamvimonvat, N.; Boheler, K.R.; Wu, J.C.; et al. Distinct roles of microRNA-1 and -499 in ventricular specification and functional maturation of human embryonic stem cell-derived cardiomyocytes. PLoS One 2011, 6, e27417. 
29. Melton, C.; Judson, R.L.; Blelloch, R. Opposing microRNA families regulate self-renewal in mouse embryonic stem cells. Nature 2010, 463, 621-626.

30. Cao, L.; Kong, L.P.; Yu, Z.B.; Han, S.P.; Bai, Y.F.; Zhu, J.; Hu, X.; Zhu, C.; Zhu, S.; Guo, X.R. MicroRNA expression profiling of the developing mouse heart. Int. J. Mol. Med. 2012, 30, 1095-1104.

31. Topkara, V.K.; Mann, D.L. Role of microRNAs in cardiac remodeling and heart failure. Cardiovasc. Drug Ther. 2011, 25, 171-182.

32. Cordes, K.R.; Srivastava, D.; Ivey, K.N. MicroRNAs in cardiac development. Pediatr. Cardiol. 2010, 31, 349-356.

33. Care, A.; Catalucci, D.; Felicetti, F.; Bonci, D.; Addario, A.; Gallo, P.; Bang, M.L.; Segnalini, P.; Gu, Y.; Dalton, N.D.; et al. MicroRNA-133 controls cardiac hypertrophy. Nat. Med. 2007, 13, 613-618.

34. Yang, Y.; Ago, T.; Zhai, P.; Abdellatif, M.; Sadoshima, J. Thioredoxin 1 negatively regulates angiotensin II-induced cardiac hypertrophy through upregulation of miR-98/let-7. Circ. Res. 2011, 108, 305-313.

35. Sun, H.; Wang, Y. Restriction of big hearts by a small RNA. Circ. Res. 2011, 108, 274-276.

36. Oka, S.; Ago, T.; Kitazono, T.; Zablocki, D.; Sadoshima, J. The role of redox modulation of class II histone deacetylases in mediating pathological cardiac hypertrophy. J. Mol. Med. 2009, 87, 785-791.

37. Ago, T.; Sadoshima, J. Thioredoxin1 as a negative regulator of cardiac hypertrophy. Antioxid. Redox Signal. 2007, 9, 679-687.

38. Arciniegas, E.; Frid, M.G.; Douglas, I.S.; Stenmark, K.R. Perspectives on endothelial-to-mesenchymal transition: Potential contribution to vascular remodeling in chronic pulmonary hypertension. Am. J. Physiol. Lung C 2007, 293, L1-L8.

39. Zeisberg, M.E.; Tarnavski, O.; Zeisberg, M.; Dorfman, A.L.; McMullen, J.R.; Gustafsson, E.; Chandraker, A.; Yuan, X.; Pu, W.T.; Roberts, A.B.; et al. Endothelial-to-mesenchymal transition contributes to cardiac fibrosis. Nat. Med. 2007, 13, 952-961.

40. Ghosh, A.K.; Nagpal, V.; Covington, J.W.; Michaels, M.A.; Vaughan, D.E. Molecular basis of cardiac endothelial-to-mesenchymal transition (EndMT): Differential expression of microRNAs during EndMT. Cell Signal. 2012, 24, 1031-1036.

41. Satoh, M.; Nakamura, M.; Akatsu, T.; Shimoda, Y.; Segawa, I.; Hiramori, K. Toll-like receptor 4 is expressed with enteroviral replication in myocardium from patients with dilated cardiomyopathy. Lab. Investig. 2004, 84, 173-181.

42. Fu, J.; Peng, C.; Wang, W.; Jin, H.; Tang, Q.; Wei, X. Let-7g is involved in doxorubicin induced myocardial injury. Environ. Toxicol. Pharmacol. 2012, 33, 312-317.

43. Marbán, E. Cardiac channelopathies. Nature 2002, 415, 213-218.

44. Yang, B.; Lin, H.; Xiao, J.; Lu, Y.; Luo, X.; Li, B.; Zhang, Y.; Xu, C.; Bai, Y.; Wang, H.; et al. The muscle-specific microRNA miR-1 regulates cardiac arrhythmogenic potential by targeting GJA1 and KCNJ2. Nat. Med. 2007, 13, 486-491.

45. Luo, X.; Lin, H.; Pan, Z.; Xiao, J.; Zhang, Y.; Lu, Y.; Yang, B.; Wang, Z. Downregulation of miRNA-1/miRNA-133 contributes to re-expression of pacemaker channel genes HCN2 and HCN4 in hypertrophic heart. J. Biol. Chem. 2008, 283, 20045-20052. 
46. Xiao, J.; Luo, X.; Lin, H.; Zhang, Y.; Lu, Y.; Wang, N.; Zhang, Y.; Yang, B.; Wang, Z. MicroRNA miR-133 represses HERG $\mathrm{K}^{+}$channel expression contributing to QT prolongation in diabetic hearts. J. Biol. Chem. 2007, 282, 12363-12367.

47. Dews, M.; Homayouni, A.; Yu, D.; Murphy, D.; Sevignani, C.; Wentzel, E.; Furth, E.E.; Lee, W.M.; Enders, G.H.; Mendell, J.T.; et al. Augmentation of tumor angiogenesis by a Myc-activated microRNA cluster. Nat. Genet. 2006, 38, 1060-1065.

48. Fish, J.E.; Santoro, M.M.; Morton, S.U.; Yu, S.; Yeh, R.F.; Wythe, J.D.; Ivey, K.N.; Bruneau, B.G.; Stainier, D.Y.R.; Srivastava, D. MiR-126 regulates angiogenic signaling and vascular integrity. Dev. Cell 2008, 15, 272-284.

49. Wurdinger, T.; Tannous, B.A.; Saydam, O.; Skog, J.; Grau, S.; Soutschek, J.; Weissleder, R.; Breakefield, X.O.; Krichevsky, A.M. MiR-296 regulates growth factor receptor overexpression in angiogenic endothelial cells. Cancer Cell 2008, 14, 382-393.

50. Lee, D.Y.; Deng, Z.; Wang, C.H.; Yang, B.B. MicroRNA-378 promotes cell survival, tumor growth, and angiogenesis by targeting $\mathrm{SuFu}$ and Fus-1 expression. Proc. Natl. Acad. Sci. USA 2007, 104, 20350-20355.

51. Wang, S.; Olson, E.N. AngiomiRs-key regulators of angiogenesis. Curr. Opin. Genet. Dev. 2009, 19, 205-211.

52. Kuehbacher, A.; Urbich, C.; Zeiher, A.M.; Dimmeler, S. Role of dicer and drosha for endothelial microRNA expression and angiogenesis. Circ. Res. 2007, 101, 59-68.

53. Suárez, Y.; Fernández-Hernando, C.; Pober, J.S.; Sessa, W.C. Dicer dependent microRNAs regulate gene expression and functions in human endothelial cells. Circ. Res. 2007, 100, 1164-1173.

54. Otsuka, M.; Zheng, M.; Hayashi, M.; Lee, J.D.; Yoshino, O.; Lin, S.; Han, J. Impaired microRNA processing causes corpus luteum insufficiency and infertility in mice. J. Clin. Investig. 2008, 118, 1944-1954.

55. Bae, O.N.; Wang, J.M.; Baek, S.H.; Wang, Q.; Yuan, H.; Chen, A.F. Oxidative stress-mediated thrombospondin-2 upregulation impairs bone marrow-derived angiogenic cell function in diabetes mellitus. Arterioscler. Thromb. Vasc. 2013, 33, 1920-1927.

56. Poliseno, L.; Tuccoli, A.; Mariani, L.; Evangelista, M.; Citti, L.; Woods, K.; Mercatanti, A.; Hammond, S.; Rainaldi, G. MicroRNAs modulate the angiogenic properties of HUVECs. Blood 2006, 108, 3068-3071.

57. Roitbak, T.; Bragina, O.; Padilla, J.L.; Pickett, G.G. The role of microRNAs in neural stem cell supported endothelial morphogenesis. Vasc. Cell 2011, 3, 1-15.

58. Roitbak, T.; Li, L.; Cunningham, L.A. Neural stem/progenitor cells promote endothelial cell morphogenesis and protect endothelial cells against ischemia via HIF-1 $\alpha$-regulated VEGF signaling. J. Cereb. Blood Flow Metab. 2008, 28, 1530-1542.

59. Falk, E. Pathogenesis of atherosclerosis. J. Am. Coll. Cardiol. 2006, 47, C7-C12.

60. Cuaz-Pérolin, C.; Jguirim, I.; Lariqauderie, G.; Jlassi, A.; Furman, C.; Moreau, M.; Chapman, M.J.; Fruchart, J.C.; Slimane, M.N.; Mezdour, H.; Rouis, M. Apolipoprotein E knockout mice over-expressing human tissue inhibitor of metalloproteinase I are protected against aneurysm formation but not against atherosclerotic plaque development. J. Vasc. Res. 2006, 43, 493-501.

61. Ross, R. Atherosclerosis-An inflammatory disease. N. Engl. J. Med. 1999, 340, 115-126. 
62. Qin, B.; Xiao, B.; Liang, D.; Li, Y.; Jiang, T.; Yang, H. MicroRNA let-7c inhibits Bcl-xl expression and regulates ox-LDL-induced endothelial apoptosis. BMB Rep. 2012, 45, 464-469.

63. Chen, K.C.; Hsieh, I.C.; Hsi, E.; Wang, Y.S.; Dai, C.Y.; Chou, W.W.; Juo, S.H. Negative feedback regulation between microRNA let-7g and the oxLDL receptor LOX-1. J. Cell Sci. 2011, 124, 4115-4124.

64. Satoh, M.; Tabuchi, T.; Minami, Y.; Takahashi, Y.; Itoh, T.; Nakamura, M. Expression of let-7i is associated with Toll-like receptor 4 signal in coronary artery disease: Effect of statins on let-7i and Toll-like receptor 4 signal. Immunobiology 2012, 217, 533-539.

65. Kin, K.; Miyagawa, S.; Fukushima, S.; Shirakawa, Y.; Torikai, K.; Shimamura, K.; Daimon, T.; Kawahara, Y.; Kuratani, T.; Sawa, Y. Tissue- and plasma-specific microRNA signatures for atherosclerotic abdominal aortic aneurysm. J. Am. Heart Assoc. 2012, 1, e000745.

66. Satoh, M.; Shimoda, Y.; Maesawa, C.; Akatsu, T.; Ishikawa, Y.; Minami, Y.; Hiramori, K.; Nakamura, M. Activated Toll-like receptor 4 in monocytes is associated with heart failure after acute myocardial infarction. Int. J. Cardiol. 2006, 109, 226-234.

67. Synetos, A.; Toutouzas, K.; Stathogiannis, K.; Latsios, G.; Tsiamis, E.; Tousoulis, D.; Stefanadis, C. MicroRNAs in arterial hypertension. Curr. Top. Med. Chem. 2013, 13, 1527-1532.

68. Eskildsen, T.V.; Jeppesen, P.L.; Schneider, M.; Nossent, A.Y.; Sandberg, M.B.; Hansen, P.B.; Jensen, C.H.; Hansen, M.L.; Marcussen, N.; Rasmussen, L.M.; et al. Angiotensin II regulates microRNA-132/-212 in hypertensive rats and humans. Int. J. Mol. Sci. 2013, 14, 11190-11207.

69. Jackson, K.L.; Marques, F.Z.; Watson, A.M.; Palma-Rigo, K.; Nguyen-Huu, T.P.; Morris, B.J.; Charchar, F.J.; Davern, P.J.; Head, G.A. A novel interaction between sympathetic overactivity and aberrant regulation of renin by miR-181a in BPH/2J genetically hypertensive mice. Hypertension 2013, doi:10.1161/HYPERTENSIONAHA.113.01701.

70. Li, S.; Zhu, J.; Zhang, W.; Chen, Y.; Zhang, K.; Popescu, L.M.; Ma, X.; Lau, W.B.; Rong, R.; $\mathrm{Yu}, \mathrm{X}$; et al. Signature microRNA expression profile of essential hypertension and its novel link to human cytomegalovirus infection. Circulation 2011, 124, 175-184.

71. Wong, S.S.Y.; Ritner, C.; Ramachandran, S.; Aurigui, J.; Pitt, C.; Chandra, P.; Ling, V.B.; Yabut, O.; Bernstein, H.S. MiR-125b promotes early germ layer specification through Lin28/let-7d and preferential differentiation of mesoderm in human embryonic stem cells. PLoS One 2012, 7, e36121.

72. Pasha, Z.; Haider, H.K.; Ashraf, M. Efficient non-viral reprogramming of myoblasts to stemness with a single small molecule to generate cardiac progenitor cells. Plos One 2011, 6, e23667.

73. Ahmed, R.P.H.; Haider, H.K.; Buccini, S.; Li, L.; Jiang, S.; Ashraf, M. Reprogramming of skeletal myoblasts for induction of pluripotency for tumor-free cardiomyogenesis in the infarcted heart. Circ. Res. 2011, 109, 60-70.

74. Chen, X.; Liang, H.; Zhang, J.; Zen, K.; Zhang, C.Y. Secreted microRNAs: A new form of intercellular communication. Trends Cell Biol. 2012, 22, 125-132.

75. Ogawa, R.; Tanaka, C.; Sato, M.; Nagasaki, H.; Sugimura, K.; Okumura, K.; Nakagawa, Y.; Aoki, N. Adipocyte-derived microvesicles contain RNA that is transported into macrophages and might be secreted into blood circulation. Biochem. Biophys. Res. Commun. 2010, 398, 723-729. 
76. Muller, G.; Schneider, M.; Biemer-Daub, G.; Weid, S. Microvesicles released from rat adipocytes and harboring glycosylphosphatidylinositol-anchored proteins transfer RNA stimulating lipid synthesis. Cell Signal. 2011, 23, 1207-1223.

77. Deddens, J.C.; Colijn, J.M.; Oerlemans, M.I.; Pasterkamp, G.; Chamuleau, S.A.; Doevendans, P.A.; Sluijter, J.P. Circulating microRNAs as novel biomarkers for the early diagnosis of acute coronary syndrome. J. Cardiovasc. Transl. Res. 2013, doi:10.1007/s12265-013-9493-9.

78. Chen, Y.J.; Zhu, J.M.; Wu, H.; Fan, J.; Zhou, J.; Hu, J.; Yu, Q.; Liu, T.T.; Yang, L.; Wu, C.L.; et al. Circulating microRNAs as a fingerprint for liver cirrhosis. PLoS One 2013, 8, e66577.

79. Wei, C.; Henderson, H.; Spradley, C.; Li, L.; Kim, I.K.; Kumar, S.; Hong, N.; Arroliga, A.C.; Gupta, S. Circulating miRNAs as potential marker for pulmonary hypertension. PLoS One 2013, 8, e64396.

80. Long, G.; Wang, F.; Duan, Q.; Yang, S.; Chen, F.; Gong, W.; Yang, X.; Wang, Y.; Chen, C.; Wang, D.W. Circulating miR-30a, miR-195 and let-7b associated with acute myocardial infarction. PLoS One 2012, 7, e50926.

81. Li, T.; Cao, H.; Zhuang, J.; Wan, J.; Guan, M.; Yu, B.; Li, X.; Zhang, W. Identification of miR-130a, miR-27b and miR-210 as serum biomarkers for atherosclerosis obliterans. Clin. Chim. Acta 2010, 412, 66-70.

(C) 2013 by the authors; licensee MDPI, Basel, Switzerland. This article is an open access article distributed under the terms and conditions of the Creative Commons Attribution license (http://creativecommons.org/licenses/by/3.0/). 